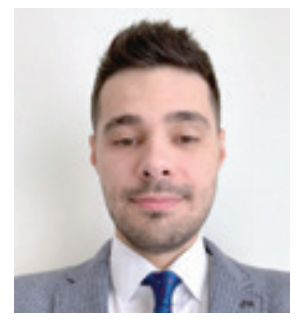

Лукас МИЧАЛОВ, доктор юридических наук, профрессор фракультета права

Университета Павла Йозефра Шафрарика в Кошице, Словакия

lab.kkonkpr@msal.ru 125993, Россия, г. Москва, ул. Садовая-Кудринская, д. 9

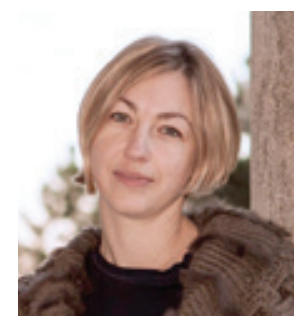

ДИана ТРЕЩАКОВА, доктор юридических наук, профрессор фракультета права Университета Павла Йозефа Шафрарика в Кошице, Словакия lab.kkonkpr@msal.ru 125993, Россия, г. Москва, ул. Садовая-Кудринская, д. 9

\section{ЭТИЧЕСКИЕ АСПЕКТЫ И ЗАЩИТА ПЕРСОНАЛЬНЫХ ДАННЫХ ПРИ ИСПОЛНЕНИИ НАКАЗАНИЯ В ВИДЕ ОГРАНИЧЕНИЯ СВОБОДЫ ${ }^{1}$}

\begin{abstract}
Аннотация. Ограничение свободы в настоящее время является частью системы наказаний в Словацкой Республике и выступает проявлением так называемого реституционного правосудия. Реституционное правосудие представлено в форме альтернативных мер наказания, которые назначаются в случае незначительности правонарушений и противопоставляются реальному лишению свободы. Альтернативные меры наказания могут включать те из них, которые не влекут за собой лишения свободы, связанного с изоляцией осужденного. Преимущество альтернативных мер наказания состоит в том, что осужденный избавляется от пагубных последствий тюремного заключения. Преступник не подвергается негативным аспектам этого вида наказания и остается интегрированным в общество, будучи в состоянии поддерживать социальные, семейные и трудовые отношения, что может значительно улучшить средство правовой защиты преступника.

В настоящее время существует много нерешенных вопросов, связанных с исполнением наказания в виде ограничения свободы, в частности с его исполнением посредством электронного мониторинга, включая защиту персональных данных, полученных с помощью электронного оборудования для мониторинга.
\end{abstract}

Ключевые слова: ограничение свободы, электронный мониторине, вид наказания, EC, разработка.

DOI: 10.17803/2311-5998.2020.66.2.160-172
(ㄱ) Л. Мичалов,

Д. Трещакова, 2020
1 Статья получена при поддержке и является результатом научно-исследовательского проекта Агентства по поддержке научных исследований и разработок в Словацкой Республике в рамках проекта № APVV-16-0362 «Приватизация уголовного права — предметное, процедурное, криминологическое и организационные: технические аспекты». 
LUCAS MICHALOV,

Doctor of Law, Professor, Faculty of Law, University of Pavel Joseph Shafarik in

Kosice, Slovakia

lab.kkonkpr@msal.ru

125993, Russia, Moscow, ul. Sadovaya-Kudrinskaya, 9

DIANA TRESHCHAKOVA,

Doctor of Law, Professor, Faculty of Law,

University of Pavel Joseph Shafarik in Kosice, Slovakia

lab.kkonkpr@msal.ru

125993, Russia, Moscow, ul. Sadovaya-Kudrinskaya, 9

\title{
ETHICAL ASPECTS AND PERSONAL DATA PROTECTION IN THE EXECUTION OF HOME PRISON PENALTY
}

\begin{abstract}
The home prison penalty is currently a part of the sanction system in the Slovak Republic and serves as a manifestation of so-called restorative justice. Restorative justice is represented by alternative sentences that are distinguished from real imprisonment for minor offences. Alternative penalties may include penalties that do not involve the deprivation of liberty associated with the isolation of a convicted person. The advantage of alternative sentences is that the offender is spared the destructive effects of imprisonment. The offender is not exposed to the negative aspects of this punishment and remains integrated into the society, being able to continue to maintain social, family and working relations, which can significantly improve the protection from the offender.

At present, there are many unresolved issues regarding the execution of the punishment of home prison penalty, especially its execution through electronic monitoring, including the protection of personal data obtained through electronic monitoring equipment. Thus, the purpose of this article is to focus on these issues and present the authors' views.

Keywords: home prison penalty, electronic monitoring, type of punishments, $E U$, elaboration
\end{abstract}

\section{1. Разработка теории наказания в виде ограничения свободы}

Наказание в виде ограничения свободы прошло постепенное развитие. Этот институт использовался в прошлом, особенно в отношении людей, которые были слишком влиятельными, чтобы подвергнуться реальному лишению свободы, например, наследственных правителей, видных политических деятелей, религиозных лидеров, чье заключение могло привести к мятежу.

Первое упоминание об ограничении свободы - это задержание апостола Павла. Многие бывшие президенты были приговорены к тюремному заключению за преступления против своих стран, например, Пол Пот (Камбоджа), Рафаэль

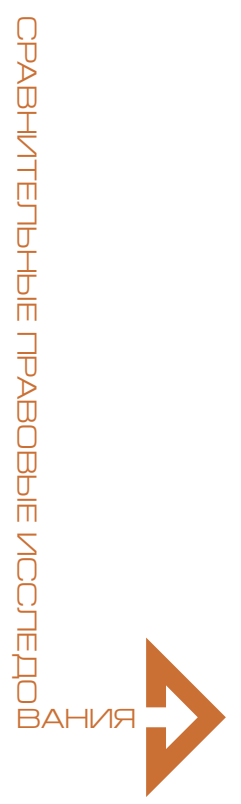


Видела (Аргентина), Хабиб Бургиба (Тунис), Аунг Сан Су Чжи (Бирма). Бывший диктатор Аугусто Пиночет был ограничен в свободе по приказу. Бывший лидер находился в домашнем заключении последние 16 лет своей жизни. Бывший премьер-министр Советского Союза Никита Хрущев находился в домашнем заключении семь лет до своей смерти после отставки в 1964 г. ${ }^{2}$

Даже в историческом развитии наказания в виде ограничения свободы было ясно, что без технического контроля этот вид наказания будет неэффеективен. В середине 1960-х гг. первое электронное устройство мониторинга было разработано гарвардским психологом доктором Ральфом Швицгебелем, который работал в Научном комитете по психологическим экспериментам в Гарвардском университете. В 1964 г. он разработал радиотелеметрическое устройство весом 1 кг, состоявшее из батареи и передатчика и передававшее сигналы, которые можно было проследить на расстояние до 400 метров и определить местонахождение пользователя. Доктор Швицгебель предположил, что его изобретение может обеспечить более гуманную и более дешевую альтернативу задержанию для многих людей, вовлеченных в процесс отправления правосудия.

Это устройство было запатентовано в 1969 г., однако вошло в практику только в 1977 г., когда судья Джек Лав из Альбукерке, штат Нью-Мексико, вдохновленный эпизодом из мультфильма «Человек-паук», обнаружил возможное использование электронного мониторинга. Судья Лав убедил Майкла Госса, специалиста по электронике, изготовить и сконструировать электронное устройство управления. В 1983 г. судья Лав впервые приговорил преступника к ограничению свободы с электронным контролем. Впоследствии другие государства стали использовать этот институт. Электронные системы наблюдения росли самыми быстрыми темпами в США, и к 1988 г. они уже были внедрены в 32 странах, в общей сложности с помощью электронного мониторинга было отслежено 2300 правонарушителей.

Однако ограничение свободы - не совсем новый институт даже в Словацкой Республике. Он уже применялся в Уголовном кодексе № 117/1852. Ограничение свободы, по сути, является альтернативой реальному заключению «первой инстанции» и может быть назначено, если у преступника нет судимости. Он должен взять на себя обязательство не выходить из дома под каким-либо предлогом, в противном случае он должен исполнить оставшуюся часть своего заключения в тюрьме из-за нарушения обязательства. Иногда клятва была необходима, иногда присутствовал охранник.

\section{2. Действующее законодательство}

Наказание в виде ограничения свободы было введено в действие в словацком законодательстве после редакции Уголовного кодекса с 1 января 2006 г. Мы можем выделить два типа ограничения свободы: «фронт-энд» и «бэк-энд». Ограничение свободы типа «фронт-энд» означает, что преступник может провести все время наказания дома. Тип «бэк-энд» означает, что преступнику сначала назначается реальное лишение свободы, а в случае надлежащего поведения преступник мо-

2 Rajnič M. Trest domáceho väzenia v systéme trestov // Justičná revue. 2009. 61. Č. 6-7. 
жет провести заключительную стадию наказания дома. Тип «бэк-энд» регулируется словацким Уголовным кодексом с 2016 г.

Ограничение свободы считается альтернативой наказанию в виде лишения свободы за менее тяжкие преступные деяния, такое наказание может быть назначено преступнику на срок до четырех лет. Уголовный кодекс регулирует, что суд может назначить ограничение свободы в качестве наказания за преступление, где верхний предел наказания тюремного заключения составляет максимум десять лет. Уголовный кодекс регулирует сроки назначения наказания в виде ограничения свободы, которые должны выполняться в совокупности.

Наказание в виде ограничения свободы может быть назначено, если:

а) с учетом характера преступления, совершенного преступником, тюремное заключение не является необходимым в силу обстоятельств преступления, связанных с личностью преступника;

б) правонарушитель дал письменное заявление о проживании в жилище по указанному адресу в указанное время и оказании необходимой помощи при проведении проверки и контроля;

в) выполнены условия проведения контроля техническими средствами.

При назначении наказания в виде ограничения свободы суд должен принять во внимание критерии оценки, касающиеся характера и важности совершенного преступления, а также правонарушителя. В случае правонарушений суд оценивает метод совершения преступного деяния, его последствия, обстоятельства совершения деяния, степень вины и мотивы правонарушителя. Суд должен рассмотреть характер преступной деятельности, личные и семейные условия преступника в будущем и возможности повторной социализации. Другое условие, представляющее сущность наказания в виде ограничения свободы, соответствует письменному заявлению правонарушителя, в котором говорится, что преступник останется по указанному адресу и обеспечит необходимое сотрудничество во время контроля ${ }^{3}$.

Осужденный преступник обязан оставаться в своем жилище, включая соседние помещения, вести достойную жизнь и выдерживать контроль с помощью технических средств в течение срока исполнения наказания в виде ограничения свободы в течение срока, установленного судом. Суд, выносящий решение об ограничение свободы, должен указать точное место ограничения свободы, в котором должен находиться осужденный, в приговоре. Судья также должен указать в приговоре точное время, когда осужденный должен оставаться в месте жительства. Судебная практика показала, что обязательство оставаться в жилище распространяется на рабочие дни недели и вне рабочего времени в период с 7.30 вечера до 6.00 утра. Необходимо обеспечить, чтобы осужденный выполнял надлежащую работу и вел семейную жизнь во время исполнения наказания в виде ограничения свободы.

На время отбывания наказания в виде ограничения свободы лицо может покинуть свое жилище только с предварительного согласия сотрудника службы

3 Tóthová V., Ferenčíková S. Innovation in criminal policy of imposing alterantive sanctions in Slovak Republic // P. Hájek, \& O. Vít (ed.). CBU International Conference Proceedings. Prague : CBU Research Institute, 2019. P. 661—670. 
пробации и посредничества и только по настоятельным причинам и в течение необходимого времени. Это время засчитывается.

Если осужденный не исполняет обязанности, наложенные судом, и ограничения, вытекающие из наказания в виде ограничения свободы, суд заменяет наказание в виде ограничения свободы или его часть на тюремное заключение. Уголовный кодекс предусматривает способ замены наказания в виде ограничения свободы на безусловное лишение свободы в пропорции 1:1 после предварительного слушания осужденного лица. Это означает, что один из ожидаемых дней наказания в виде ограничения свободы соответствует одному дню тюремного заключения, и суд должен принять решение о способе такого тюремного заключения.

\section{3. Контроль с помощью электронного мониторинга}

Существенным условием наложения штрафа на ограничение свободы является выполнение условий технического контроля. Контроль исполнения наказания в виде ограничения свободы техническими средствами, несомненно, может считаться новшеством в отношении контроля исполнения санкций в целом.

Электронный мониторинг в Словацкой Республике был введен в действие в соответствии с Законом № 78/2015 Сб. о контроле за исполнением отдельных решений техническими средствами в новой редакции. Закон вступил в силу 1 января 2016 г., и в тот же день в Словакии была создана электронная система мониторинга лиц. Закон № 78/2015 регулирует технические средства, условия их использования и порядок контроля.

Электронный мониторинг представляет собой систему контроля за соблюдением определенных запретов, ограничений и распоряжений, а также санкций и определенных мер защиты как форм уголовно-правовых санкций. В соответствии с действующим регулированием, мы выделяем шесть типов мониторинга, где различные типы технических средств используются в каждом виде мониторинга.

Эксплуатационные расходы технических средств несут государство и частично контролируемое лицо. Размер его доли определяется в исполнительной команде. Технические средства являются государственной собственностью, связанной с так называемой центральной системой мониторинга. Именно это позволяет проверять соблюдение режима задержания с помощью сигналов, передаваемых техническими средствами, а также регистрировать случаи нарушения безопасности и эксплуатации 4 .

Эфффективный контроль над исполнением приговоров без лишения свободы может быть обеспечен с помощью технических средств и электронного мониторинга. Проект электронной системы мониторинга обвиняемых и осужденных (ESMO), совместно финансируемый Европейским Союзом из Европейского фонда регионального развития через операционную программу «Информатизация компании» была запущена Министерством юстиции Словацкой Республики в 2013 г.

${ }^{4}$ Klátik J. Uplatňovanie restoratívnej justície a elektronického monitoringu na Slovensku a vo vybraných štátoch Európskej únie. I. Košické dni trestného práva - Perspektívy vývoja európskeho trestného práva. Košice : Univerzita Pavla Jozefa Šafárika v Košiciach, 2018. 
Закон о контроле за исполнением определенных решений техническими средствами различает больше видов технических средств. Для исполнения наказания в виде ограничения свободы необходимо использовать:

1) персональное идентификационное устройство;

2) устройство для проверки наличия на месте исполнения приговора;

3) устройство сотрудника службы пробации и посредничества.

Основным элементом электронного мониторинга и технических средств является устройство идентификации личности. В настоящее время оно выполнено в форме браслета, который надевается на тело наблюдаемого лица, обычно на его лодыжку. Контролируемое лицо обязано допускать прикрепление этого устройства к своему телу в течение всего срока исполнения решения техническими средствами. Любые попытки помешать этому устройству или повредить, уничтожить его оцениваются как инциденты безопасности. Это общее устройство используется при исполнении наказания в виде ограничения свободы путем наложения различных соответствующих ограничений и обязательств.

Устройство для проверки присутствия в месте отбывания наказания, используемое при отбывании наказания в доме, находится в жилище (доме, квартире, месте жительства) контролируемого лица, и на основе связи с устройством идентификации личности можно проверить наличие контролируемого лица в указанное время в определенном месте. В настоящее время это устройство имеет вид домашней станции мониторинга. Это устройство связывается с устройством персональной идентификации, радиочастотный сигнал которого принимает и оценивает присутствие и отсутствие контролируемого лица в указанном месте и в указанное время в соответствии с решением суда. В случае нарушения условий данное устройство сообщит об этом фракте в соответствующий центр, который передаст эту информацию сотруднику по вопросам пробации и посредничества.

Устройство сотрудника службы пробации и посредничества, используемое соответствующим сотрудником, - это техническое устройство, позволяющее осуществлять контроль за запретом, ограничением или обязательством «на месте» путем выявления присутствия устройства для персональной идентификации в радиусе примерно 300 м по географическому признаку и, таким образом, обнаружения людей, которые имеют это устройство, подключенное к телу. Например, в конкретном случае можно будет проверить, находится ли контролируемое лицо в указанное время в указанном месте.

\section{4. Этические аспекты электронного мониторинга}

Электронное устройство мониторинга также включает в себя автоматизированную обработку данных осужденных преступников. Это инновационный способ исполнения наказания с помощью электронного устройства, который также можно классифицировать с использованием искусственного интеллекта.

В настоящее время, особенно в эпоху четвертой промышленной революции, искусственный интеллект внедряется во всех сферах деятельности, включая исполнение наказаний осужденных преступников. Именно из-за внедрения искусственного интеллекта в исполнение наказаний необходимо изучить природу искусственного интеллекта и его правовые и этические аспекты. 
Можно сказать, что искусственный интеллект — это научная дисциплина, которая занимается разработкой алгоритмов и машин, демонстрирующих признаки интеллектуального поведения. Учитывая непрекращающееся развитие искусственного интеллекта, необходимо нормативно решить связанные с ним вопросы и принять меры предосторожности для предотвращения злоупотреблений им.

В июне 2018 г. Европейская комиссия создала группу экспертов - Al HLEG, в которую вошли общественные, отраслевые и академические деятели. Эта группа подготовила документ в поддержку стратегии Европейской комиссии по искусственному интеллекту и робототехнике. Однако документ является результатом работы группы и не может рассматриваться как официальная позиция Комиссии. Документ фокусируется в основном на этических ценностях и устойчивости как с технической, так и с социальной стороны. Развитие и интеграция искусственного интеллекта в жизнь должны основываться на четырех этических принципах, основанных на Хартии основных прав Европейского Союза, а именно:

- предотвращение вреда. Принцип основан на статье о неприкосновенности человека как в фризической, так и в психической фрорме, особенно с точки зрения медицины и биологии (например, запрет на репродуктивное клонирование человека, полный текст которого можно найти в ст. 3 Устава);

- уважение к человеческой автономии. Система искусственного интеллекта не может ослабить или иным образом негативно повлиять на нее. Человек обладает способностью контролировать систему и вмешиваться в процесс;

- справедливость. Принимает разные фрормы, но развитие системы должно быть справедливым с точки зрения двух измерений. Основное измерение включает равное распределение затрат и выгод, а также обеспечение того, чтобы человек не подвергался дискриминации или предвзятому отношению. Процедурное измерение включает в себя возможность отклонить решения системы искусственного интеллекта и людей и настаивать на исправлении. Для этой цели должна быть возможность определить орган, ответственный за принятие решения, и объяснить процесс принятия решения;

- ясность. Это необходимо для обеспечения того, чтобы система искусственного интеллекта всегда была прозрачной, чтобы процедуры можно было идентифицировать и открыто сообщать о целях системы.

Эти этические принципы привели к этическим требованиям, которые должны соблюдаться при реализации так называемого «заслуживающего доверия искусственного интеллекта» 5 .

7 декабря 2018 г. Европейская комиссия представила Европейскому Парламенту, Европейскому Совету, Европейскому экономическому и социальному комитету и Комитету регионов сообщение о Скоординированном плане искусственного интеллекта, сопровождающем Скоординированный план развития и использования искусственного интеллекта, разработанного государствамичленами (в составе Европейской группы по промышленности и искусственному интеллекту), Норвегией, Швейцарией и Комиссиейб.

5 Klátik J. Op. cit.

6 Coordinated Artificial Intelligence Plan // URL: https://data.consilium.europa.eu/doc/document/ ST-6177-2019-INIT/sk/pdf. 
Скоординированный план охватывает четыре ключевые области, а именно:

а) увеличение инвестиций;

б) рассекречивание и накопление большего количества данных (что является

«сырьем» для искусственного интеллекта);

в) поддержка таланта;

г) обеспечение доверия.

Они определили приоритетные области общественного интереса, такие как здравоохранение, транспорт и мобильность, безопасность, безопасность и энергетика, а также важные экономические сектора, такие как производство и финансовые услуги.

Поэтому вопросы, которые нужно задать о развертывании искусственного интеллекта, имеют не только техническое, но и этическое измерение. Первой из этических проблем является прозрачность и ясность решений по искусственному интеллекту, что связано с проблемой отслеживания возможных ошибок при автоматическом принятии решений машиной. Программы, которые предсказывают преступное поведение, являются примерами того, насколько малопрозрачным является решение, основанное на искусственном интеллекте, и как оно может оказать серьезное влияние на людей. Это могут быть, например, алгоритмы, которые оценивают, какие лица наиболее вероятно вовлечены в незаконную деятельность, или оценивают вероятность повторения осужденных преступников. Упомянутые инструменты включают в себя систему, которая рассчитывает степень опасности осужденных для общества. В этом случае было показано, что некоторые решения об искусственном интеллекте носят дискриминационный и расовый характер. Одной из причин может быть то, что искусственный интеллект приобретает свои возможности из реальной действительности ${ }^{7}$.

Рекомендация CM/Rec (2014) 4 Комитета министров государств-членов об электронном мониторинге также может применяться для решения этических вопросов, связанных с электронным мониторингом осужденных. В настоящей Рекомендации рассматриваются этические вопросы в части пятой Приложения (часть V), в которой содержатся ст. 26-28. В соответствии со ст. 26 возраст, инвалидность и другие соответствующие конкретные условия или личные обстоятельства каждого подозреваемого или правонарушителя должны учитываться при решении вопроса о том, может ли и при каких условиях исполняться электронный мониторинг.

В соответствии со ст. 27 ни при каких обстоятельствах электронное контрольное оборудование не может быть использовано для причинения преднамеренного фризического или психического вреда или страданий подозреваемому или правонарушителю.

В соответствии со ст. 28 правила, касающиеся использования электронного мониторинга, должны периодически пересматриваться с целью учета технологических достижений в этом районе, с тем чтобы избежать чрезмерного вмешательства в частную и семейную жизнь подозреваемых, правонарушителей и других затрагиваемых лиц .

7 URL: https://vedanadosah.cvtisr.sk/etika-a-umela-inteligencia.

8 The Recommendation CM/Rec (2014) 4 of the Committee of Ministers of the Member States on electronic monitoring. 


\section{5. Защита персональных данных и электронный мониторинг}

Быстрые технологические разработки и глобализация поставили новые задачи по защите персональных данных. Масштабы сбора и обмена персональными данными значительно возросли. Технология позволяет обрабатывать личные данные в беспрецедентных масштабах для осуществления таких действий, как предотвращение, расследование, выявление или преследование за совершение уголовных преступлений или исполнение уголовных наказаний.

В соответствии с пар. 26 Директивы (ЕС) 2016/680 Европейского Парламента и Совета от 27 апреля 2016 г. о защите фризических лиц в отношении обработки персональных данных компетентными органами в целях предотвращения, расследования, обнаружения или судебного преследования уголовных преступлений или исполнения уголовных наказаний, а также о свободном перемещении таких данных и отмене Рамочного решения Совета 2008/977/JHА любая обработка персональных данных должна быть законной, справедливой и прозрачной по отношению к соответствующим фризическим лицам и только для определенных целей, предусмотренных законом. Это не мешает правоохранительным органам проводить такие действия, как тайные расследования или видеонаблюдение.

Такие действия могут осуществляться в целях предотвращения, расследования, выявления или судебного преследования за совершение уголовных преступлений или исполнения уголовных наказаний, включая защиту и предотвращение угроз общественной безопасности, если они установлены законом и представляют собой необходимую и соразмерную меру в демократическом обществе с должным учетом законных интересов соответствующего физического лица.

Физические лица должны быть осведомлены о рисках, правилах, гарантиях и правах в отношении обработки их персональных данных и о том, как осуществлять эти права. В частности, конкретные цели, для которых обрабатываются персональные данные, должны быть явными, законными и определенными во время сбора персональных данных. Персональные данные должны быть адекватными и соответствующими целям, для которых они обрабатываются. В частности, следует обеспечить, чтобы собранные персональные данные не были чрезмерными и не хранились дольше, чем это необходимо для цели, для которой они обрабатываются. Персональные данные должны обрабатываться только в том случае, если цель обработки не может быть разумно выполнена другими способами. Чтобы гарантировать, что данные не хранятся дольше, чем необходимо, контроллер должен установить временные рамки для стирания или для периодического просмотра. Эти принципы также должны применяться к электронному мониторингу осужденных преступников.

Электронный мониторинг осужденных преступников основан на использовании искусственного интеллекта и автоматизированной обработке этих данных. Данные, полученные в результате этой автоматической обработки, представляют собой личные данные осужденных и других лиц, с которыми они вступают в контакт. Это также может быть конфиденциальная информация о конфиденциальности, связано с проблемой больших данных и профилирования субъектов данных. Большие данные и профилирование субъекта данных могут пониматься как обработка больших объемов информации (не только личных данных) разных лиц, 
которая в основном состоит из анализа и объединения этих данных с помощью комплекса алгоритмов для нахождения точно определенных отношений, в результате чего в профилях, применимых к группам лиц, которые подразделяются на предварительно определенные категории лиц или группы лиц в соответствии с ожидаемым будущим поведением этих групп.

Профилирование субъектов данных определяется также в Общем регламенте Европейского Парламента и Совета (ЕС) от 27 апреля 2016 г. о защите фризических лиц при обработке персональных данных и о свободном перемещении таких данных и отмене Директивы 95/46/EC (Общие положения о защите данных) (далее - GDPR). В соответствии со ст. 4 пар. 4 профилирование означает «любую фрорму автоматизированной обработки персональных данных, состоящую из использования персональных данных для оценки определенных личных аспектов, относящихся к физическому лицу, в частности для анализа или прогнозирования аспектов, касающихся работы этого физического лица, экономической ситуации, здоровья, личных предпочтений, интересов, надежности, поведения, местоположения или движения.

В соответствии с GDPR субъект данных должен иметь право не подчиняться решению, которое может включать в себя оценку личных аспектов, касающихся его или ее, которая основана исключительно на автоматизированной обработке и имеет правовые последствия без какого-либо вмешательства человека. Автоматическое принятие решений и профилирование на основе специальных категорий персональных данных должно быть разрешено только при определенных условиях (например, расовая, этническая или религиозная информация). Исключение составляют общественные интересы и согласие субъекта данных.

Как упоминалось выше, защита фризических лиц в отношении обработки персональных данных компетентными органами в целях предотвращения, расследования, выявления или судебного преследования за совершение уголовных преступлений или исполнения уголовных наказаний, а также от свободного перемещения таких данных изменено указанным актом EC, который также касается автоматической обработки персональных данных. Это регулируется Директивой (EC) 2016/680 Европейского Парламента и Совета от 27 апреля 2016 г. о защите физических лиц в отношении обработки персональных данных компетентными органами в целях предотвращения, расследования и обнаружения, или судебное преследование за совершение уголовных преступлений или исполнение уголовных наказаний, а также за свободное перемещение таких данных и отмене Рaмочного решения Совета 2008/977/JHA (далее - направление) в связи с GDPR.

Как отмечает Михок, важным вопросом является изучение возможности использования искусственного интеллекта в электронном мониторинге в уголовном правосудии в соответствии со ст. 22 пар. 1. Правонарушители с электронным

9 Hučková R., Sokol P., Rózenfeldová L. 4th industrial revolution and challenges for european law (with special attention to the concept of digital single market) // EU and comparative law issues and challenges series: Eu law in context — adjustment to membership and challenges of the enlargement : International Scientific Conference.Osijek : Sveučilište Josipa Jurja Strossmayera u Osijeku, 2018. S. 201-215 //URL: https://hrcak.srce.hr/ojs/index.php/eclic/ issue/view/313/Vol2. 
мониторингом GDPR имеют право не подвергаться решению, основанному исключительно на автоматизированной обработке, включая профилирование ${ }^{10}$.

Решение, основанное на автоматизированной обработке данных, полученных с помощью электронного мониторинга, что также соответствует требованиям GDPR и Директивы, должно быть принято лицом или органом, назначенным для этой цели, после проверки и оценки информации. Конечно, будет целесообразно, чтобы при оценке осужденного лица не учитывались данные, которые дискриминируют осужденного преступника, а также данные и инфрормация, не относящиеся к нему, но касающиеся, например, членов семьи.

В соответствии с пар. 37, 38 Директивы субъект данных должен иметь право не подчиняться решению, оценивающему личные аспекты, которое основано исключительно на автоматизированной обработке и создает неблагоприятные правовые последствия или имеет существенное воздействие. В любом случае на такую обработку должны распространяться надлежащие меры предосторожности, включая предоставление конкретной информации субъекту данных и право на вмешательство человека, в частности, для выражения своей точки зрения, для получения разъяснений, возможности оспорить решение.

Профрилирование, приводящее к дискриминации физических лиц на основе личных данных, которые по своей природе являются особенно чувствительными в отношении основных прав и свобод, должно быть запрещено в соответствии с условиями, изложенными в ст. 21 и 52 Устава. Персональные данные, которые по своей природе особенно чувствительны в отношении основных прав и свобод, заслуживают особой защиты, поскольку контекст их обработки может создавать значительные риски для основных прав и свобод. Эти персональные данные должны включать персональные данные, раскрывающие расовое или этническое происхождение.

Такие личные данные не должны обрабатываться, если только обработка не подлежит соответствующим гарантиям прав и свобод субъекта данных, установленным законом, и разрешена в случаях, разрешенных законом. Соответствующие гарантии прав и свобод субъекта данных могут включать в себя возможность сбора этих данных только в связи с другими данными о соответствующем физическом лице, возможность надежно защитить собранные данные, более строгие правила доступа персонала компетентного органа, право на данные и запрет на передачу этих данных.

Также важно решить вопрос, как обращаться с данными, полученными из электронного мониторинга. Здесь можно выделить две группы данных и информации. Одной из них являются данные, которые необходимы для принятия решения. Оно не может быть основано на специальных категориях персональных

10 Žulová J.Profilovanie a automatizované rozhodovanie (nielen) v pracovnoprávnych vzt'ahoch // Švec M.,Bulla M. (eds.) Práca 4.0, digitálna spoločnost' a pracovné právo [online]. [citované 06.09.2019] Bratislava: Friedrich Ebert Stiftung (zastúpenie v SR).2018.S. 49—60 //URL: http:// www.fes.sk/fileadmin/user_upload/aktuality/2018/Praca_4.0.pdf ;Mihók P. Vybrané právne a etické aspekty umelej inteligencie pri elektronickom monitoringu obvinených a odsúdených osôb //Suchoža J., Husár J., Hučková R. (eds.) Právo, obchod, ekonomika. IX.Košice : Univerzita P. J. Šafárika v Košiciach, 2019. 
данных. Вторая группа полученных данных — это те, которые не являются необходимыми для принятия решения или не касаются заинтересованного лица. Это могут быть, например, члены семьи или другие лица, с которыми осужденный преступник вступает в контакт. Эти данные не должны использоваться и должны быть отброшены.

Защита личных данных в электронном мониторинге осужденных преступников не должна осуществляться без таких институтов, как анонимизация и псевдонимизация, которые должны использоваться в электронном мониторинге ${ }^{11}$.

Закон о защите личных данных № 18/2018 Сб. в Словакии, следуя модели GDPR, вводит и определяет юридический термин «псевдонимизация». В соответствии с п. 5, h «псевдонимизация означает обработку персональных данных таким образом, что персональные данные больше не могут быть отнесены к конкретному субъекту данных без использования дополнительной информации, при условии, что такая дополнительная информация хранится отдельно и подлежит техническим и организационным мерам по обеспечению того, чтобы персональные данные не были отнесены к идентифицированному или идентифицируемому фризическому лицу».

\section{Заключение}

Электронный мониторинг используется для проверки осужденных преступников, часто также рецидивистов, которые находятся на грани общества. Тем не менее они всегда являются людьми, имеют права и свободы. Наконец, что не менее важно, они имеют право на защиту персональных данных и конфиденциальной информации о них, а также на их конфиденциальность. В связи с этим лица, проживающие в домашнем хозяйстве с осужденным преступником, и лица, вступающие с ними в контакт, также имеют право на защиту своих личных данных и конфиденциальной информации.

Электронный мониторинг вторгается в личную жизнь осужденного преступника. Персональные данные и конфиденциальная информация собираются и впоследствии обрабатываются, используются и хранятся в электронном или бумажном виде. По этой причине важно, чтобы данные и информация были законно получены и защищены, в том числе с использованием анонимности и псевдонима. Также необходимо, чтобы только лица, указанные в законе, имели доступ к этим данным.

Учитывая тот фракт, что законодательство и на территории Словацкой Республики, и в европейском регионе недостаточно разработано в этой области, было бы целесообразно восполнить этот пробел. В противном случае электронный мониторинг осужденных преступников не будет осуществляться в соответствии с требованиями защиты персональных данных и конфиденциальной информации, а также конфиденциальности и будет нарушать основные права и свободы, вытекающие, в частности, из Устава ЕС.

11 Veselý P. Pseudonymizácia a anonymizácia osobných údajov ako požiadavka GDPR // URL: https://www.zoou.sk/33/pseudonymizacia-a-anonymizacia-osobnych-udajov-akopoziadavka-gdpr-uniqueidmRRWSbk196FPkyDafLfWAJWc7pG-Xzb6XqJG803ba64/. 


\section{БИБЛИОГРАФИЯ}

1. Hučková R., Sokol P., Rózenfeldová L.4th industrial revolution and challenges for european law (with special attention to the concept of digital single market) // EU and comparative law issues and challenges series: Eu law in context adjustment to membership and challenges of the enlargement : International Scientific Conference. Osijek : Sveučilište Josipa Jurja Strossmayera u Osijeku, 2018. S. 201-215 // URL: https://hrcak.srce.hr/ojs/index.php/eclic/issue/view/313/ Vol. 2.

2. Klátik J. Uplatňovanie restoratívnej justície a elektronického monitoringu na Slovensku a vo vybraných štátoch Európskej únie. I. Košické dni trestného práva Perspektívy vývoja európskeho trestného práva. - Košice : Univerzita Pavla Jozefa Šafárika v Košiciach, 2018.

3. Rajnič $M$. Trest domáceho väzenia v systéme trestov // Justičná revue. — 2009. — 61. - Č. 6-7.

4.Suchoža J., Husár J., Hučková R. (eds.) Právo, obchod, ekonomika. — IX. Košice : Univerzita P. J. Šafárika v Košiciach, 2019.

5. Tóthová V., Ferenčíková S. Innovation in criminal policy of imposing alterantive sanctions in Slovak Republic // P. Hájek, \& O. Vít (ed.). CBU International Conference Proceedings. - Prague : CBU Research Institute, 2019. P. $661-670$.

6. VeselýP.Pseudonymizácia a anonymizácia osobných údajov ako požiadavka gdpr // URL:https://www.zoou.sk/33/pseudonymizacia-a-anonymizacia-osobnych-udajovako-poziadavka-gdpr-uniqueidmrrwsbk196fpkydaflfwajwc7pg-xzb6xqjg803ba64/.

7. ŽulováJ.Profilovanie a automatizované rozhodovanie (nielen) v pracovnoprávnych vzt'ahoch. in švec, m. - bulla, m. (eds). Práca 4.0, digitálna spoločnost' a pracovné právo. - Bratislava : Friedrich ebert stiftung, 2018. 